\title{
An association between feather damaging behavior and corticosterone metabolite excretion in captive African grey parrots (Psittacus erithacus)
}

Pierluca Costa ${ }^{1}$, Elisabetta Macchi ${ }^{1}$, Emanuela Valle ${ }^{1}$, Michele De Marco $^{1}{ }^{\text {, }}$ Daniele M Nucera ${ }^{2}$, Laura Gasco $^{2}$, Achille Schiavone ${ }^{\text {Corresp. } 1}$

${ }^{1}$ Department of Veterinary Science, University of Turin, Grugliasco (TO), Italy

2 Department of Agricultural, Forest and Food Sciences, University of Turin, Grugliasco (TO), Italy

Corresponding Author: Achille Schiavone

Email address: achille.schiavone@unito.it

Background. African grey parrots (Psittacus erithacus) are kept as pets and are frequently hand-reared. It has been observed that hand-reared African grey parrots may develop behavioral disorders such as feather damaging behavior (FDB). It is well known that chronic stress is involved in behavioral disorders in captive parrots. The main glucocorticoid in birds is corticosterone; its quantification provides information about adrenocortical activity and is considered to be a reliable indicator of stress levels in birds. We analyzed the differences in the excretion of corticosterone metabolites (CM) in the droppings of African grey parrots characterized by 1 . different rearing histories (parent rearing vs. hand rearing) and 2 . the presence or absence of FDB in hand-reared parrots. Methods. A total of 82 African grey parrots that were kept in captivity were considered. According to breeding methods, three groups of birds were defined: 1 . The parent-reared (PR) parrots included birds kept in pairs ( $n=30$ pairs) with a conspecific partner of the opposite sex. All of these birds were healthy and never showed FDB signs. 2. The healthy hand-reared parrots $(\mathrm{H}-\mathrm{HR})$ included pet parrots individually kept, that were hand-reared and did not display any sign of FDB ( $n=11,7$ males and 4 females). 3.The FDB hand-reared parrot (FDB-HR) included pet parrots individually kept, that were hand-reared and displayed FDB ( $n=11,7$ males and 4 females). Droppings were collected in the morning over three alternating days in autumn 2014 and spring 2015. The CM were determined using a multi-species corticosterone enzyme immunoassay kit (K014; Arbor Assays ${ }^{\circledR}$, Ann Arbor, MI). Split-plot repeated-measure ANOVA was used to examine any differences using group, season and group $\times$ season as the main factors. Results. Different quantities of CM in droppings were found for the three groups. The mean CM value was $587 \mathrm{ng} / \mathrm{g}$ in the PR parrots, $494 \mathrm{ng} / \mathrm{g}$ in the H-HR parrots and $1744 \mathrm{ng} / \mathrm{g}$ in the FDB-HR parrots, irrespective of the season. The excretion of CM in FDB-HR was significantly higher than in PR or H-HR 
parrots. CM in droppings were not influenced by the season (autumn vs. spring); furthermore, the interaction between group and sampling season was not significant. Limited to the H-HR and FDB-HR groups, a trend in the significance of the difference in the mean $\mathrm{CM}$ excreted by male and female birds was observed, with the levels excreted by males being higher than those excreted by females. When the effect of age was considered (in the two separate groups), there was a statistically significant positive correlation only for H-HR. Conclusions. The highest amount of CM excretion was found in FDB-HR parrots, and a positive correlation between age and CM excretion was found in $\mathrm{H}$ HR. Given that the CM excretion of both PR and H-HR parrots was similar in our study, future research is recommended to investigate the specific aspects of hand-rearing to improve parrot welfare. 


\section{An association between feather damaging behavior and 2 corticosterone metabolite excretion in captive African grey 3 parrots (Psittacus erithacus)}

4

5 Costa Pierluca ${ }^{1}$, Macchi Elisabetta ${ }^{1}$, Emanuela Valle $^{1}$, De Marco Michele ${ }^{1}$, Daniele Nucera ${ }^{2}$,

6 Laura Gasco ${ }^{2}$, Schiavone Achille ${ }^{1}$

$7{ }^{1}$ Department of Veterinary Sciences, University of Turin, Grugliasco, Turin, Italy

8 2Department of Agricultural, Forest and Food Sciences, University of Turin, Grugliasco, Turin,

9 Italy

10

11 Corresponding Author:

12 Elisabetta Macchi

13 Largo Paolo Braccini 2, Grugliasco, Turin, 10095, Italy

14 Email address: elisabetta.macchi@unito.it 


\section{Abstract}

17 Background. African grey parrots (Psittacus erithacus) are kept as pets and are frequently handreared. It has been observed that hand-reared African grey parrots may develop behavioral disorders such as feather damaging behavior (FDB). It is well known that chronic stress is involved in behavioral disorders in captive parrots. The main glucocorticoid in birds is corticosterone; its quantification provides information about adrenocortical activity and is considered to be a reliable indicator of stress levels in birds. We analyzed the differences in the excretion of corticosterone metabolites (CM) in the droppings of African grey parrots characterized by 1. different rearing histories (parent rearing vs. hand rearing) and 2. the presence or absence of FDB in hand-reared parrots.

Methods. A total of 82 African grey parrots that were kept in captivity were considered. According to breeding methods, three samples of birds were defined: 1 . The parent-reared (PR) parrots included birds kept in pairs ( $\mathrm{n}=30$ pairs) with a conspecific partner of the opposite sex. All of these birds were healthy and never showed FDB signs. 2. The healthy hand-reared parrots (H-HR) included pet parrots individually kept, that were hand-reared and did not display any sign of FDB ( $\mathrm{n}=11,7$ males and 4 females). 3.The FDB hand-reared parrot (FDB-HR) included pet parrots individually kept, that were hand-reared and displayed FDB ( $n=11,7$ males and 4 females).

Droppings were collected in the morning over three alternating days in autumn 2014 and spring 2015. The CM were determined using a multi-species corticosterone enzyme immunoassay kit (K014; Arbor Assays ${ }^{\circledR}$, Ann Arbor, MI). Split-plot repeated-measure ANOVA was used to examine any differences using group, season and group $\times$ season as the main factors. 
38 Results. Different quantities of CM in droppings were found for the three samples. The mean

$39 \mathrm{CM}$ value was $587 \mathrm{ng} / \mathrm{g}$ in the PR parrots, $494 \mathrm{ng} / \mathrm{g}$ in the H-HR parrots and $1744 \mathrm{ng} / \mathrm{g}$ in the

40

41

FDB-HR parrots, irrespective of the season. The excretion of CM in FDB-HR was significantly higher than in PR or H-HR parrots. CM in droppings were not influenced by the season (autumn vs. spring); furthermore, the interaction between group and sampling season was not significant. Limited to the H-HR and FDB-HR groups, a trend in the significance of the difference in the mean $\mathrm{CM}$ excreted by male and female birds was observed, with the levels excreted by males being higher than those excreted by females. When the effect of age was considered (in the two separate samples), there was a statistically significant positive correlation only for H-HR.

Conclusions. The highest amount of CM excretion was found in FDB-HR parrots, and a positive correlation between age and CM excretion was found in H-HR. Given that the CM excretion of both PR and H-HR parrots was similar in our study, future research is recommended to investigate the specific aspects of hand-rearing needed to improve parrot welfare.

Keywords: African grey parrot; stress; corticosterone; feather picking, feather plucking.

\section{Introduction}

African grey parrots (Psittacus erithacus) are kept as pets in private households because of their sociability and also for their ability to imitate human speech.

African grey parrots may be hand-reared, and this practice has been increasingly carried out over the last 30 years. Based on the hand-rearing method used, hand-reared parrots can be divided into different groups according to the incubation system (natural vs. artificial) and the age of removal from the nest (at hatch, less than approximately 5 weeks or more than 
61 approximately 5 weeks) (Schmid, Doherr \& Steiger, 2006). In contrast to parent-reared parrots,

62 which imprint toward conspecifics (Glendell, 2003), hand-reared parrots imprint on humans and

63

64

65

66

67

seem to be socially dependent on them. The exact consequences of the different hand-rearing methods on the development of behavior in adult birds are still not clear. However, it has been observed that hand-reared grey parrots may develop behavioral disorders, such as aggressiveness, feather picking, stereotypies or abnormal sexual behaviors, and thus it is expected that they are prone to develop such behavioral disorders (Schmid, Doherr \& Steiger, 2006). Moreover, is has been observed that hand-reared chicks that were less than 5 weeks old when removed from the nest developed stereotypies more often than chicks that stayed longer with their parents (Schmid, Doherr \& Steiger, 2006).

Feather damaging behavior (FDB) includes plucking, chewing, fraying and/or biting, and it results in the loss of or damage to feathers (van Zeeland et al., 2009; van Zeeland et al., 2013). FDB in parrots is usually self-inflicted and generally includes all mutilation of the feathers accessible to the bird's beak (Harrison, 1986). Grindlinger (1991) estimated that approximately $10 \%$ of the captive bird population suffered from FDB. Kinkaid et al. (2013), in a sample of 538 parrots, found an FDB prevalence of $15.8 \%$. Our group previously conducted a study considering this classification, which showed a notable difference in the FDB prevalence in the two different populations of parrots. The parent-raised population $(n=1488)$ showed an FDB prevalence of $1.3 \%$, while the pet parrot population $(n=292)$ showed an FDB prevalence of $17.5 \%$ (Costa et al., 2016). FDB has rarely been observed in the wild and usually occurs in captive birds when they reach sexual maturity (Wedel, 1999), even though some authors have reported the onset of FDB prior to the occurrence of sexual maturity (Jayson, Williams \& Wood, 2014). FDB occurs in many species of parrots, and it has been observed in African grey parrots 
84 (Psittacus erithacus) and cockatoos (Cacatua spp.) (Clubb et al., 2007; Jayson, Williams \&

85 Wood, 2014; Peng et al., 2014), Amazona spp. parrots (Garner et al., 2006), Ara spp. and

86

87

88

89

90

91

92

93

94

95

96

97

98

99

100

101

102

103

104

105
Agapornis spp. (Costa et al., 2016), crimson-bellied conures (Pyrrhura perlata, van Hoek \& Ten

Cate, 1998) and other psittacine species. It has been suggested that FDB could be a coping strategy for negative affective states (e.g., stress and boredom) and/or living in a suboptimal environment (Rosskpopf \& Woerpel, 1996; Levine \& Practice, 2003). In many cases, these patterns may represent an exaggeration or expansion of normal behavior, resulting from inadequate environmental stimuli and/or early weaning and/or social isolation (Garner et al., 2006; Schimd, Doherr \& Steiger, 2006; van Zeeland et al., 2013).

It is well known that chronic stress is involved in behavioral disorders in captive parrots (Ferreira et al., 2015; Owen \& Lane, 2006). In vertebrates, the front-line hormones for overcoming stressful situations are $\beta$-endorphin, glucocorticoids and catecholamines (Ayala et al., 2012; Johnstone, Reina \& Lill, 2012; Livingston, 2010; Möstl, Rettenbacher \& Palme, 2005; Schmidt et al., 2010). The main glucocorticoid in birds is corticosterone; its quantification provides information about adrenocortical activity (Ferreira et al., 2015) and is considered to be a reliable indicator of stress levels in birds (Dehnhard et al., 2003; Hartup et al., 2004; Young \& Hallford, 2013), giving important insight into the welfare status of an individual or a group of animals (Lane, 2006), especially when used in conjunction with other parameters such as behavior. The analysis of fecal corticosterone is preferred over blood sampling because is less invasive and can cause fewer stress responses (Nemeth et al., 2016) without compromising the welfare assessment (Hamilton \& Weeks, 1985; Le Maho et al., 1992). Several authors have reported a correlation between the concentrations of plasma glucocorticoids and their metabolites 
106 in the feces of mammals (Möstl et al., 1999; Palme et al., 1999; Stead, Meltzer \&Palme, 2000) or 107 in the droppings of birds (Dehnard et al., 2003).

108 Owen \& Lane (2006) measured corticosterone in the droppings of African grey parrots, 109 and they observed that the corticosterone level in the excreta of FDB parrots was higher than that 110 of healthy pet parrots. However, these authors did not consider the sex and age of the parrots or 111 the season in which the samples were taken. The purpose of the present study was to compare the 112 excretion of corticosterone metabolites (CM) in the droppings of hand-reared (with or without 113 FDB) and in parent-reared African grey parrots (kept in pairs for reproduction) during autumn 114 and spring. For the hand-reared parrots, the influence of sex and age on the amount of 115 corticosterone in droppings was also considered. An increase in CM in hand-reared parrots with 116 FDB was expected. Furthermore, we aimed to determine if healthy hand-reared parrots and 117 parent-reared parrots display similar patterns in CM excretion.

119 Materials \& Methods

Animal and selection criteria

121 The study was based on a web questionnaire used in a previous study (Costa et al., 2016)

122 that was addressed to the owners of all species of pet parrots. The questionnaire was distributed 123 throughout Italy through online parrot association sites, social networks and e-mails in 124 collaboration with the Italian Psittacine Club (known as the "Club degli Psittacidi" 125 http://psittacidi.webservice-4 $\mu . c o m /)$ and the Italian Association of Parrot Breeders (known as 126 the "Associazione Italiana Allevatori Pappagalli", http://www.assopappagalli.it/). In the present 127 study, we only considered African grey parrots because this was the most represented species 
128 among the Italian respondents (Costa et al., 2016) and because this species is considered to be

129 very sensitive to FDB (Jayson, Williams \& Wood, 2014; Schmid et al., 2006).

All birds considered in our study were born in captivity, and no wild-caught birds were

used. A total of 82 African grey parrots were considered. To be included in the study, the birds

had to be at least thirty-six months old, so that only birds that had a fully formed character and

sexual behavioral patterns were considered. Based on the different methodologies of rearing at

134 the neonatal stage, hand-reared and parent-reared parrots were considered. Among the hand-

reared parrots, a further distinction was made between parrots displaying FDB and parrots not

displaying FDB. According to these criteria, three samples of birds were defined: 1. Parent-

reared (PR) parrots; 2. Healthy hand-reared parrots (H-HR); 3. FDB hand-reared parrots (FDB-

$138 \mathrm{HR})$.

139

1. The parent-reared (PR) parrots (Figure 1a) included birds kept in pairs ( $\mathrm{n}=30$ pairs)

with a conspecific partner of the opposite sex, since they were specifically reared for reproduction. These birds were reared by their biological parents, and contact with humans was minimal and related only to their care and daily management. The PR parrots were permanently

143 housed in a standard parrot cage with a minimum volume of $1 \mathrm{~m}^{3}$ and exposed to natural light variation. All of these birds were healthy and never showed signs of FDB. All of the birds included in this sample were housed in the same facility. We included this sample that we considered a valid control for stress coping since (usually considered well-balanced birds that

147 have learnt all of the specific behavioral patterns of their species). We included this sample since parent-reared captive parrots are usually considered well-balanced birds that have learnt all of the specific behavioral patterns of their species (Schimd, Doherr \& Steiger, 2006). 

birds ( 7 males and 4 females). Each bird was individually kept by a owner. clinical problems.

The H-HR were age ( \pm 2 years) and sex matched with the FDB-HR. Both H-HR and FDB-HR parrots lived mostly outside a cage without any other parrots and had a close

to commercial diets formulated specifically for parrots that were supplemented with fruit and vegetables. The owners of all of the parrots included in the study completed a questionnaire about the care and management of the parrots and, only for FDB-HR parrots, the main body regions affected by FDB.

Droppings sampling and analysis season. The droppings were collected in the morning (9:00 - 11:00 AM) for three days on alternating days. This time frame was chosen with the intention to reduce the effect of daily

171 patterns in CM excretion. The samples were collected directly from the cleaned bottom of the

172 bird's habitual cage where the parrot lived. For PR parrots, the dropping samples represent a 
173 pool of the excreta from the parrot pairs, whereas the droppings were individually collected for

174 the H-HR and FDB-HR parrots. The 3-day samples were pooled, stored in 50-mL plastic tubes

175 and immediately frozen at $-20^{\circ} \mathrm{C}$ until analysis. A total of 30,11 and 11 samples were collected

176 at each sampling time for the PR, H-HR and FDB-HR parrots, respectively.

177

To extract steroids, we used the methanol-based procedure described by Palme et al.

178 (2013) with slight modifications. Briefly, the droppings were lyophilized, weighed, and 179 completely crushed, and two aliquots of the samples $(0.25 \mathrm{~g}$ each $)$ were placed into extraction 180 tubes, which were then sealed with a Teflon cap and stored at $-20^{\circ} \mathrm{C}$. Each aliquot was 181 thoroughly mixed for 30 min using a multivortex with one $\mathrm{mL}$ of $80 \%$ methanol (Sigma Aldrich, St. Louis, MO). The suspension was then centrifuged at $500 \mathrm{~g}$ for $20 \mathrm{~min}$ and the supernatant was recovered. An aliquot $(0.5 \mathrm{~mL})$ of the supernatant was transferred into a new vial and evaporated at $50^{\circ} \mathrm{C}$ for $14 \mathrm{~h}$. After evaporation, the dried extracts were stored at room temperature in dark boxes for 15 days and then kept at $-80^{\circ} \mathrm{C}$ until they were assayed. One day before the $\mathrm{CM}$ analyses, the dried extracts were re-diluted in $0.5 \mathrm{~mL}$ of $80 \%$ methanol. An aliquot of the extract was diluted to 1:10 in the assay buffer (Arbor Assays ${ }^{\circledR}$, Ann Arbor, MI). The mixture was then vortexed and left to rest for 5 min twice to ensure complete steroid solubility. The CM were determined using a multi-species corticosterone enzyme immunoassay kit (K014; Arbor Assays ${ }^{\circledR}$, Ann Arbor, MI). All of the analyses were repeated twice. The interand intra-assay coefficients of variation were less than $10 \%$ (6\% and $8 \%$, respectively). The sensitivity of the assay was $11.2 \mathrm{ng} / \mathrm{g}$ droppings. All of the droppings samples were analyzed at multiple dilutions $(1: 4,1: 8,1: 16$ and 1:32), and all regression slopes were parallel to the standard curve $\left(\mathrm{r}^{2}=0.983\right)$. The mean recovery rate of corticosterone added to dried excreta was $95.8 \%$. 
$196100 \%$ with corticosterone, $12.3 \%$ with desoxycorticosterone, $0.62 \%$ with aldosterone, $0.38 \%$

197 with cortisol and $0.24 \%$ with progesterone. The concentration of CM was expressed as ng/g of 198 droppings dry matter.

199

200

Data analysis

201

The CM of the PR, HP and FDB-P parrots were compared. Before testing for group 202 differences, the normality of the data distribution and the homogeneity of variance were assessed using the Shapiro-Wilk test and Levene's test, respectively. Split-plot repeated-measure ANOVA was used to examine any differences using one within-subject variable (season) and one between-subject variable (the three samples of birds) and considering the interaction between these main effects. When the main effect was significant, a Tukey's post hoc test was performed the H-HR and FDB-HR groups, a t-test and a correlation analysis (Pearson's $r$ ) were performed, respectively. The data are presented as the mean and the pooled standard error of the mean (SEM). Statistical significance was set at 0.05 , and a trend of significance was considered at $\mathrm{p}<0.1$. All statistical analyses were performed using SPSS version 15.0 for Windows (SPSS Inc., Chicago, IL, USA).

\section{Results}

The average age of the birds was $8.1 \pm 1.7,7.9 \pm 5.4,7.8 \pm 5.4$ years for PR, H-HR and FDBHR parrots respectively. The average volume of the aviary cages in which the birds belonging to

217 the PR group were kept was $4.85 \mathrm{~m}^{3}$. The average volume of the cages of each H-HR and FDB218 HR parrot was $1.70 \mathrm{~m}^{3}$, although they were kept outside the cage on a daily basis for at least five 
219 hours, thus living in close contact with their owners. The main region affected by FDB in the

220 FDB-HR birds was the chest $(90.9 \%)$ (Figure $2 a)$, and this was followed by the wings $(18.2 \%)$

221 (Figure 2b), the shoulders and the rump (9.1\%) (Figure 2c). No sign of FDB was observed on the

222 head.

223

Different quantities of $\mathrm{CM}$ in droppings were found for the three samples of African grey

224

225

226

227

228

229

230

231

232

233

234

235

236

237

238

239

240

241

parrots. The mean CM value was $587 \mathrm{ng} / \mathrm{g}$ in the PR parrots, $494 \mathrm{ng} / \mathrm{g}$ in the $\mathrm{H}-\mathrm{HR}$ parrots and $1744 \mathrm{ng} / \mathrm{g}$ in the FDB-HR parrots, irrespective of the season (Table 1). The excretion of CM in FDB-HR parrots was higher than in PR and H-HR parrots $(\mathrm{p}<0.001)$. CM in droppings were not influenced by the season (autumn vs spring); furthermore, the interaction between parrot groups and the sampling season was not significant (Table 1).

To explore the effect of sex on CM excretion in the H-HR and FDB-HR samples, a t-test was performed, considering the mean $\mathrm{CM}$ amount (autumn and spring) for each bird, given the non-significance of the within-subject effect (sampling season); moreover, in these samples, a correlation analysis (Pearson's $r$ ) using the same response variable was conducted to assess the effect of age on CM excretion. The results showed that there was a trend in the difference in the mean $\mathrm{CM}$ excreted by male and female birds, with the levels of males being higher than those presented in females: HP, mean of males $=554$, mean of females $=388(\mathrm{t}=1.851, \mathrm{p}=0.097)$; FDB$\mathrm{HR}$, mean of males $=1852$, mean of females $=1556(\mathrm{t}=1.906, \mathrm{p}=0.089)$. When the effect of age was considered (in the two separate populations), there was a statistically significant positive correlation only for H-HR ( $r=0.609 \mathrm{p}=0.047)$; in contrast, no correlation was found for FDB-HR $(r=0.398, \mathrm{p}=0.225)$.

\section{Discussion}



approximately three times higher than that of PR and H-HR parrots, irrespective of the season of sampling. Moreover, no differences were found in CM excretion between H-HR and PR parrots,

245 the latter of which were kept in pairs for reproduction and so they can maintain sexual and social 246 activity.

247 Our results confirm the findings of Owen \& Lane (2006), which showed higher CM in 248 the droppings of FDB-HR parrots than in control parrots. To the best of our knowledge, the 249 paper of Owen \& Lane (2006) is the only study comparing the CM excretion in droppings of 250 FDB and non-FDB African grey parrots (261 ng/g and $75 \mathrm{ng} / \mathrm{g}$, respectively). Our results

251

252 253

254 255 confirm these observations in terms of significant differences between FDB-HR and H-HR parrots, but the magnitude of the values measured in our study was more than 6 times higher than those observed by Owen \& Lane (2006). In the study of Owen \& Lane (2006), the control group was composed of ten birds that were kept all together in a large aviary, so they presumably maintained their social and sexual activity. In contrast, in our study, we considered two samples of parrots that did not display FDB: PR and H-HR, which both display similar levels of CM excretion. Parent reared parrots are usually considered well balanced birds since parent rearing methods let them to learn all the specific behavior pattern, which is a great benefit for their welfare (Schmid, Doherr \& Steiger, 2006). The link between FDB and the corticosterone levels of excreta has also been observed by Peng et al. (2014) in two cases of FDB in sulphur-crested cockatoos (Cacatua galerita); the authors found a decrease in corticosterone levels after treatments that consisted of socialization, a training program, medication and feeding enrichments. Even though we did not measure the environmental or enrichment management and the activity of parrots included in our study, it has been previously demonstrated that parrots with 
265 FDB display higher activity compared to parrots without FDB in a number of behavioral tests,

266 suggesting that FDB is a proactive stress response pattern; under chronic stress conditions,

267 proactive birds seemed to be more prone to develop behavioral disorders (van Zeeeland et al.,

268 2013). In some cases, FDB can lead to medical problems and reflects underlying skin

269 pathologies that itch or irritate (Garner et al., 2008) and/or cause health problems related to tissue

270 damage, hemorrhage, infection, or hypothermia (Meehan, Millam \& Mench, 2003; van Zeeland

271 et al., 2009). Thus, psychogenic feather picking can be considered to be a sign of compromised

272 welfare due to the physical problems it may cause as well as the psychological distress it may

273 reflect (Meehan, Millam \& Mench, 2003). In the present study, the body area most affected by

274 FDB was the chest, and the head was not affected by FDB. The presence of feathers in good

275 condition in areas of the body that are not directly reachable (i.e., the head) by the birds is one of

276 the criteria that has been used to make a distinction between FDB and other skin or plumage

277 diseases (Galvin, 1983; Harison, 1986; Westerhof \& Lumeij, 1987).

278 The higher CM excretion in the FDB-HR parrots than in the H-HR and PR parrots,

279 suggest an increase in adrenal cortical activity (Möstl et al., 2002). The adrenal glands have a

280 key role in the hormonal response to short-term and chronic stress, which result in an increase in

281 glucocorticoid secretion (Möstl et al., 2002). The measurement of CM in bird droppings has been

282 proposed to assess the welfare status of birds (Meehan, Garner \& Mench, 2004; Van Zeeland et

283 al., 2009; Cussen \& Mench, 2015; Young \& Hallford, 2013; Ferreira et al., 2015; Shepherdson et

284 al., 2004), the results of such analyses are hard to interpret because the biological perspective

285 suggests only an increase in adrenocortical activity. For these reasons, the importance of these

286 data could lead to misinterpretation because they are a result of a complex interaction between a 
287 wide range of physiological, endocrine and behavioral variables that occur simultaneously

288 (Gaskins \& Bergman, 2011; Cussen \& Mench, 2015; Van Zeeland et al., 2009). In our sample of hand-reared parrots, a trend in the significance of the difference in the mean $\mathrm{CM}$ excreted between male and female birds was found for both H-HR and FDB-HR parrots, with the levels excreted by males being higher than those excreted by females. In contrast, Ferreira et al. (2015) did not find any gender effect in the CM excretion of blue-fronted parrots (Amazona aestiva). Furthermore, a positive correlation between age and CM excretion was found for H-HR parrots. However, these results should be considered with caution in both studies due to the small sample sizes and the different species considered. The demographic features of FDB (i.e., sexual maturation) and gender predisposition (female $>$ male) have been reviewed by van Zeeland et al. (2009), who state that the literature on this topic is related to field studies of small group of animals and that consequently larger surveys are thus necessary to confirm these results.

FDB is observed mainly in hand-reared parrots, occurring in from 10 to $17.5 \%$ of individuals (Grindlinger 1991; Kinkaid et al., 2013; Costa et al., 2016), while in parent-reared parrots, FDB does not occur or occurs rarely (approximately 1\%) (Costa et al., 2016). Handrearing has been considered to be a risk factor in the incidence of FDB (Costa et al., 2016; Schmid, Doherr \& Steiger, 2006). Furthermore, social isolation and sexual behavior frustration can have important roles in the development of abnormal behavior (Lantermann, 1989; Harrison, 1994; van Hoek \& Ten Cate, 1998; Wedel, 1999; Fox, 2006; Jayson, Williams \& Wood, 2014). According to Fox (2006), abnormal sexual imprinting and a strong social preference for humans may cause behavioral problems in pet parrots, which are most likely more prone to 309 inappropriately direct sexual behavior toward their owners. Since both H-HR and FDB-HR were 
310 in social and reproductive isolation in our study, this suggests that there is something different

311 about their management that could be linked to environmental enrichment or breeding methods;

312 thus, from an animal welfare perspective, it is fundamental to deeply research the risk factors

313 that are involved in the incidence of FDB.

314

315 Conclusions

316 In the present study, we analyzed the differences in CM excretion between African grey

317 parrots characterized by 1 . different rearing histories (parent rearing vs. hand rearing) and 2. the 318 presence or absence of FDB in hand-reared parrots.

The highest amount of CM excretion was found in FDB-HR parrots, and a positive correlation between age and CM excretion was found in H-HR.

Given that the CM excretion of both PR and H-HR parrots was similar in our study,

322 future research is recommended to focus on the specific aspects of hand-rearing needed to 323 improve the welfare of parrots.

\section{Acknowledgements}

The authors would like to thank the parrot owners for providing samples and for filling out the questionnaire for the data collection effort as well as the various veterinary surgeons for diagnostic confirmations. The authors are also grateful to Dr. Valentina Ballabio, Miss Federica Ardizzone and Mr. Simone Durigon for the support provided during the organization of the research. 


\section{References}

333 Ayala I, Martos NF, Silvan G, Gutierrez-Panizo C, Clavel JG, Illera JC. 2012. Cortisol, 334 adrenocorticotropic hormone, serotonin, adrenaline and noradrenaline serum concentrations in 335 relation to disease and stress in the horse. Research in veterinary science 93(1):103-107. DOI 336 10.1016/j.rvsc.2011.05.013.

337 Clubb SL, Cray C, Arheart KL, Goodman M. 2007. Comparison of selected diagnostic 338 parameters in African grey parrots (Psittacus erithacus) with normal plumage and those 339 exhibiting feather damaging behavior. Journal of avian medicine and surgery 21(4): 259-264. 340 DOI 10.1647/2006-039R.1.

341 Costa P, Macchi E, Tomassone L, Ricceri F, Bollo E, Scaglione FE, Tarantola M, De Marco M,

342 Prola L, Bergero D, Schiavone A. 2016. Feather picking in pet parrots: sensitive species, risk 343 factor and ethological evidence. Italian Journal of Animal Science 1-8. DOI $344 \quad 10.1080 / 1828051 X .2016 .1195711$.

345 Cussen VA, Mench JA. 2015. The relationship between personality dimensions and resiliency to 346 environmental stress in orange-winged amazon parrots (Amazona amazonica), as indicated by 347 the development of abnormal behaviors. PLoS One 10(6):1-11. DOI 348 10.1016/j.anbehav.2013.12.022.

349 Dehnhard M, Schreer A, Krone O, Jewgenow K, Krause M, Grossmann R. 2003. Measurement 350 of plasma corticosterone and fecal glucocorticoid metabolites in the chicken (Gallus domesticus),

351 the great cormorant (Phalacrocorax carbo), and the goshawk (Accipiter gentilis). General and 352 comparative endocrinology 131(3):345-352. DOI 10.1016/S0016-6480(03)00033-9.

353 Ferreira JCP, Fujihara CJ, Fruhvald E, Trevisol E, Destro FC, Teixeira CR, Pantoja JCF, 354 Schmidt EMS, Palme R. 2015. Non-invasive measurement of adrenocortical activity in blue- 
355 fronted parrots (Amazona aestiva, Linnaeus, 1758). PLoS ONE 10:1-14. DOI

356 http://dx.doi.org/10.1371/journal.pone.0145909.

357 Fox R. 2006. Hand-Rearing: Behavioral Impacts and Implications for Captive Parrot Welfare. In:

358 Luescher AU, ed. Manual of parrot behavior. USA: Blackwell, 83-91.

359 Galvin C. 1983. The feather picking bird. In: Kirk, R.W. (Ed.), Current Veterinary Therapy VIII

360 Small Animal Practice. Philadelphia: WB Saunders, 646-652.

361 Garner JP, Meehan CL, Famula TR, Mench JA. 2006. Genetic, environmental, and neighbor

362 effects on the severity of stereotypies and feather picking in Orange-winged Amazon parrots

363 (Amazona amazonica): An epidemiological study. Applied Animal Behaviour Science 96(1):153-

364 168. DOI 10.1016/j.applanim.2005.09.009.

365 Garner MM, Clubb SL, Mitchell MA, Brown L, 2008. Feather-picking psittacines:

366 Histopathology and species trends. Veterinary pathology 45:401-408.

367 Gaskins LA, Bergman L. 2011. Surveys of avian practitioners and pet owners regarding common

368 behavior problems in psittacine birds. Journal of Avian Medicine and Surgery 25: 111-118. DOI

369 http://dx.doi.org/10.1647/2010-027.1.

370 Glendell G. 2003. Obedience Training for Flighted Pet Parrots. AFA Watchbird 30:8-11.

371 Grindlinger HM. 1991. Compulsive feather picking in birds. Archives of general psychiatry

372 48(9):857. DOI 10.1001/archpsyc.1991.01810330081012.

373 Hamilton GD, Weeks JrHP. 1985. Cortisol and aldosterone comparisons of cottontail rabbits

374 collected by shooting, trapping, and falconry. Journal of Wildlife Diseases 21(1):40-42. DOI

$37510.7589 / 0090-3558-21.1 .40$.

376 Harrison GJ, 1986. Disorders of the integument. In: Harrison, G.J., Harrison, L.R., Ritchie, B.W.

377 (Eds.), Clinical Avian Medicine and Surgery. Philadelphia: WB Saunders, 509-524. 
378 Harrison GJ. 1994. Perspective on parrots behavior. In Avian medicine, principles and 379 application. Ritchie Harrison and Harrison, Wingers publishing.

380 Hartup BK, Olsen GH, Czekala NM, Paul-Murphy J, Langenberg, JA. 2004. Levels of fecal 381 corticosterone in sandhill cranes during a human-led migration. Journal of wildlife diseases $38240(2): 267-272$. DOI 10.7589/0090-3558-40.2.267.

383 Jayson SL, Williams DL and Wood JLN. 2014. Prevalence and risk factors of feather plucking in 384 African grey parrots (Psittacus erithacus erithacus and Psittacus erithacus timneh) and cockatoo 385 (Cacatua spp.). Journal of Exotic Pet Medicine 23:250-257. DOI 10.1053/j.jepm.2014.06.012.

386 Johnstone CP, Reina RD, Lill A. 2012. Interpreting indices of physiological stress in free-living 387 vertebrates. Journal of Comparative Physiology B 182(7):861-879. DOI 10.1007/s00360-012$388 \quad 0656-9$.

389 Kinkaid, HMY, Mills DS, Nichols SG, Meagher RK, Mason GJ 2013. Feather-damaging 390 behaviour in companion parrots: an initial analysis of potential demographic risk factors. Avian 391 Biology Research 6(4):289-296. DOI 10.3184/175815513X13803574144572.

392 Lane J. 2006. Can non-invasive glucocorticoid measures be used as reliable indicators of stress 393 in animals? Animal Welfare 15(4):331-342.

394 Lantermann W. 1989. Modifikation und Störungen des arteigenen Verhaltens bei 395 Grosspapageien in Menschenobhut. In: Der praktische Tierarzt 11:5-12.

396 Le Maho Y, Karmann H, Briot D, Handrich Y, Robin JP, Mioskowski E, Farni, J. 1992. Stress in 397 birds due to routine handling and a technique to avoid it. American Journal of Physiology398 Regulatory, Integrative and Comparative Physiology 263(4):775-781. 
399 Levine BS, Practice CA. 2003. Common disorders of Amazons, Australian parakeets, and 400 African grey parrots. In: Seminars in Avian and Exotic Pet Medicine. WB Saunders. 12(3):125401 130. DOI 10.1053/saep.2003.00020-3.

402 Livingston A. 2010. Pain and analgesia in domestic animals. In: Comparative and veterinary 403 pharmacology. Berlin: Springer Berlin Heidelberg, 159-189.

404 Meehan CL, Millam JR, Mench JA, 2003. Foraging opportunity and increased physical 405 complexity both prevent and reduce psychogenic feather picking by young Amazon parrots. 406 Applied Animal Behaviour Science 80:71-85. doi: 10.1016/S0168-1591(02)00192-2.

407 Meehan CL, Garner JP, Mench JA. 2004. Environmental enrichment and development of cage 408 stereotypy in Orange-winged Amazon parrots (Amazona amazonica). Developmental 409 Psychobiology 44(4):209-218. DOI 10.1002/dev.20007.

410 Möstl EM, Messmann S, Bagu E, Robia C, Palme R. 1999. Measurement of glucocorticoid 411 metabolite concentrations in faeces of domestic livestock. Journal of Veterinary Medicine Series 412 A 46:621-631. DOI 10.1046/j.1439-0442.1999.00256.x.

413 Möstl EM, Palme R. 2002. Hormones as indicators of stress. Domestic Animal Endocrinology 414 Journal 23:67-74. DOI S0739724002001467.

415 Möstl E, Rettenbacher S, Palme R. 2005. Measurement of corticosterone metabolites in birds' 416 droppings: An analytical approach. Annals of the New York Academy of Sciences, 1046(1), 17417 34. DOI 10.1196/annals.1343.004.

418 Nemeth M, Pschernig E, Wallner B, Millesi E. 2016. Non-invasive cortisol measurements as 419 indicators of physiological stress responses in guinea pigs. PeerJ 4:e1590. DOI $420 \quad 10.7717 /$ peerj.1590. 
421 Owen DJ, Lane JM. 2006. High levels of corticosterone in feather-plucking parrots (Psittacus

422 erithacus). Veterinary Record-English Edition, 158(23):804-805. DOI 10.1136/vr.158.23.804.

423 Palme R, Robia C, Messmann S, Hofer J, Möstl E. 1999. Measurement of faecal cortisol

424 metabolites in ruminants: a non-invasive parameter of adrenocortical function. Wiener

425 Tierärztliche Monatsschrift 86(7):237-241.

426 Palme R, Rettenbacher S, Touma C, El-Bahr SM, Möstl E. 2005. Stress hormones in mammals

427 and birds: comparative aspects regarding metabolism, excretion, and noninvasive measurement

428 in fecal samples. Annals of the New York Academy of Sciences 1040(1):162-171. DOI 1589102.

429 Palme R, Touma C, Arias N, Dominchin Mf, Lepschy M. 2013. Steroid extraction: Get the best

430 out of faecal samples. Wiener Tierärztliche Monatsschrift 100: 238-246

431 Peng SJL, Hessey J, Tsay T, Fei A. C-Y 2014. Assessment and Treatment of Feather Plucking in

432 Sulphur-Crested Cockatoos Cacatua galerita. Journal of Animal and Veterinary Advances 433 13:51-61.

434 Rosskopf Jr, W. J., \& Woerpel, R. 1996. Diseases of cage and aviary birds. Williams \& Wilkins.

435 Schmid R, Doherr MG, Steiger A. 2006. The influence of the breeding method on the behaviour 436 of adult African grey parrots (Psittacus erithacus). Applied Animal Behaviour Science 98(3):293437 307. DOI 10.1016/j.applanim.2005.09.002.

438 Schmidt A, Biau S, Möstl E, Becker-Birck M, Morillon B, Aurich J, Aurich C. 2010. Changes in 439 cortisol release and heart rate variability in sport horses during long-distance road transport. 440 Domestic animal endocrinology 38(3):179-189. DOI 10.1016/j.domaniend.2009.10.002.

441 Shepherdson DJ, Carlstead KC, Wielebnowski N. 2004. Cross-institutional assessment of stress 442 responses in zoo animals using longitudinal monitoring of faecal corticoids and behaviour. 443 Animal Welfare-potters bar then wheathampstead 13:105-114. 
444 Stead SK, Meltzer DGA, Palme R. 2000. The measurement of glucocorticoid concentrations in 445 the serum and faeces of captive African elephants (Loxodonta africana) after ACTH stimulation: 446 research communication. Journal of the South African Veterinary Association 71(3):192-196.

447 Van Hoek CS, King CE. 1997. Causation and influence of environmental enrichment on feather 448 picking of the crimson-bellied conure (Pyrrhura perlata perlata). Zoo Biology 16(2):161-172. 449 DOI 10.1002/(SICI)1098-2361(1997)16:2<161::AID-ZOO6>3.0.CO;2-8.

450 Van Hoek CS, Ten Cate C. 1998. Abnormal behavior in caged birds kept as pets. Journal of 451 Applied Animal Welfare Science 1(1):51-64.

452 Van Zeeland YR, Spruit BM, Rodenburg TB, Riedstra B, van Hierden YM, Buitenhuis B, S. 453 Korteg SM, Lumeija JT. 2009. Feather damaging behaviour in parrots: A review with 454 consideration of comparative aspects. Applied Animal Behaviour Science 121(2):75-95. DOI 455 10.1016/j.applanim.2009.09.006.

456 Van Zeeland YRA, Bergers MJ, van der Valk L, Schoemaker NJ. 2013. Evaluation of a novel 457 feather scoring system for monitoring feather damaging behavior in parrots. Veterinary Journal 458 196:247-252. DOI 10.1016/j.tvj1.2012.08.020.

459 Wedel A. 1999. Ziervogel-Erkrankungen, Haltung, Futterung. Parey-Verlag, Wien 283-286.

460 Westerhof I, Lumeij JT. 1987. Feather picking in the African grey parrot. In Proceedings of the 461 European Symposium on Bird Diseases, Beerse, Belgium. Netherlands Association of Avian 462 Veterinarians 98-103.

463 Young AM, Hallford DM (2013) Validation of a fecal glucocorticoid metabolite assay to asses 464 stress in the Budgerigar (Melopsittacus ondulatus). Zoo Biology 32: 112-116. 
467
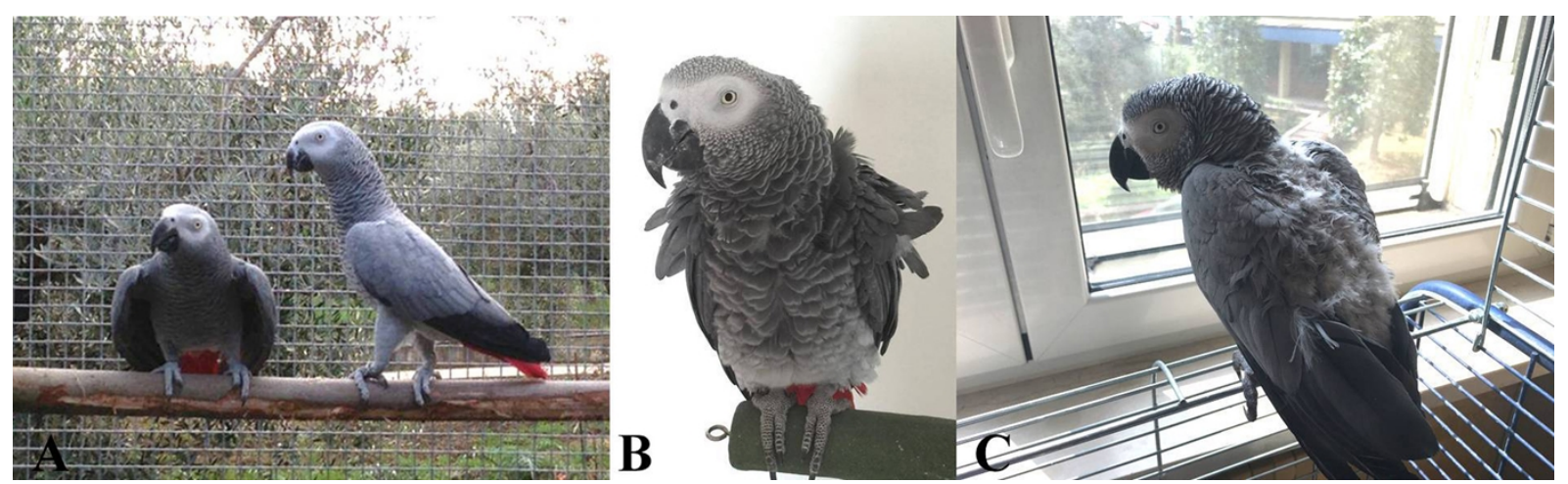

469

470

A) a parent-reared pair; B) healthy hand-reared parrot and C) hand-reared parrots that display

471 feather damaging behavior

472

473

Figure 2. Deplumation area in feather damaging behavior African grey parrots

474

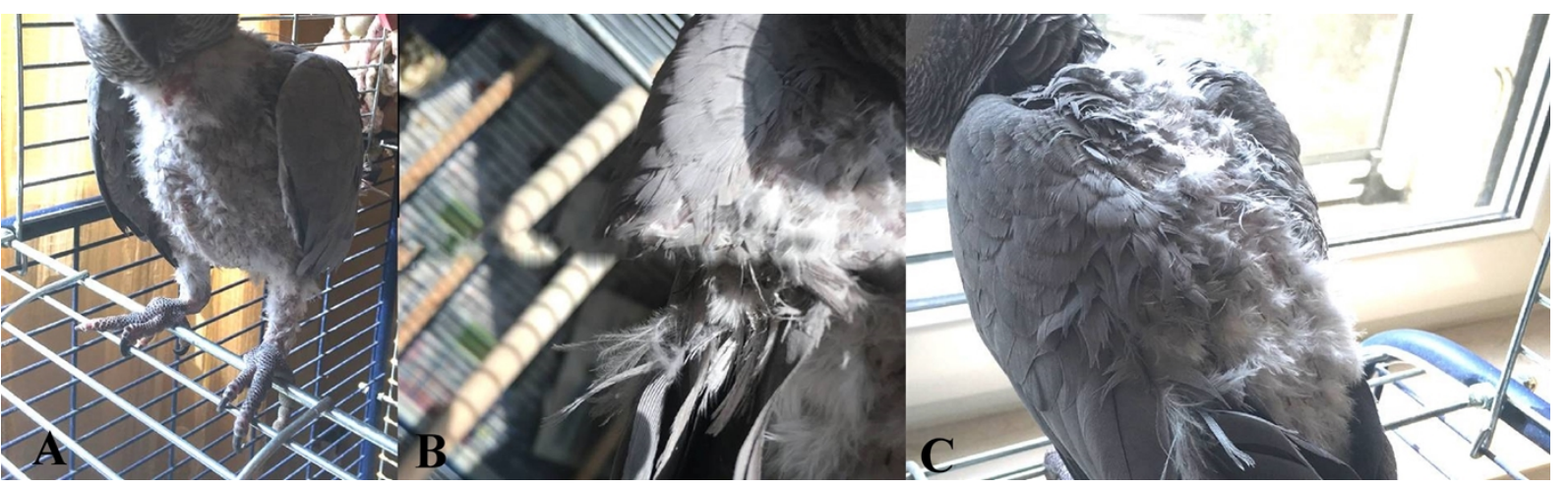

477 A) chest area; B) wings; C) shoulders and rump 
479 Table 1. Corticosterone metabolite (ng/g dry matter) excretion in the droppings of healthy

480 and FDB ${ }^{1}$ African grey parrots (Psittacus erithacus) (mean and pooled SEM)

\begin{tabular}{|c|c|c|c|c|c|}
\hline \multirow{2}{*}{ Group } & \multirow{2}{*}{ Season } & \multirow{2}{*}{ Mean } & \multirow{2}{*}{ SEM } & \multicolumn{2}{|c|}{ 95\% Confidence Interval } \\
\hline & & & & Lower Bound & Upper Bound \\
\hline \multirow[t]{3}{*}{$\overline{\mathrm{PR}^{2} \text { parrots }}$} & autumn & 617 & 25 & 558 & 676 \\
\hline & spring & 558 & 31 & 467 & 649 \\
\hline & mean & 587 & 20 & & \\
\hline \multirow[t]{3}{*}{$\mathrm{H}-\mathrm{HR}^{3}$ parrots } & autumn & 519 & 58 & 421 & 616 \\
\hline & spring & 469 & 45 & 318 & 620 \\
\hline & mean & 494 & 36 & & \\
\hline \multirow[t]{3}{*}{ FDB-HR ${ }^{4}$ parrots } & autumn & 1749 & 55 & 1652 & 1847 \\
\hline & spring & 1739 & 133 & 1589 & 1890 \\
\hline & mean & 1744 & 70 & & \\
\hline
\end{tabular}

Main effects:

\begin{tabular}{lll}
\hline Group: & $\mathrm{F}=194.477$ & $\mathrm{p}<0.0001$ \\
Season: & $\mathrm{F}=1.305$ & $\mathrm{p}=0.259$ \\
Interaction (group $\times$ season): & $\mathrm{F}=0.191$ & $\mathrm{p}=0.826$
\end{tabular}

Group contrasts (LSD test):

PR vs. H-HR parrots: $\quad \mathrm{p}=0.140$

PR vs. FDB-HR parrots: $\quad \mathrm{p}<0.0001$

HR vs. FDB-HR parrots: $\quad \mathrm{p}<0.0001$

481 글 feather damaging behavior ${ }^{2} \mathrm{PR}$ : parent-reared; ${ }^{3} \mathrm{H}-\mathrm{HR}$ : healthy hand-reared; ${ }^{4} \mathrm{FDB}-\mathrm{HR}$ : feather damaging 482 behavior hand-reared. 